\title{
Drug Induced Cutaneous Vasculitis
}

National Cancer Institute

\section{Source}

National Cancer Institute. Drug Induced Cutaneous Vasculitis. NCI Thesaurus. Code C112204.

A skin hypersensitivity reaction due to exposure to a pharmacologic substance that is characterized by raised purpuric lesions, red macules, hemorrhagic blisters and ulcerations. 